\title{
Antiplatelets in acute coronary syndrome in Poland - from guidelines to clinical practice
}

\author{
Stanisław Tubek ${ }^{1}$, Wiktor Kuliczkowski², Mariusz Gąsior ${ }^{3}$, Marek Gierlotka ${ }^{4}$, Jacek Kubica ${ }^{5}$, Andrzej Budaj ${ }^{6}$, \\ Adam Witkowski ${ }^{7}$, Krzysztof Reczuch ${ }^{1}$, Piotr Ponikowski ${ }^{1}$ \\ ${ }^{1}$ Department of Heart Diseases, Wroclaw Medical University, Wroclaw, Poland \\ ${ }^{2}$ Department of Cardiology, Wroclaw Medical University, Wroclaw, Poland \\ ${ }^{3} 3^{\text {rd }}$ Department of Cardiology, Faculty of Medical Sciences in Zabrze, Medical University of Silesia in Katowice, Poland \\ ${ }^{4}$ Department of Cardiology, Institute of Medical Sciences, University of Opole, Opole, Poland \\ ${ }^{5}$ Department of Cardiology and Internal Medicine, Collegium Medicum, Nicolaus Copernicus University, Bydgoszcz, Poland \\ ${ }^{6}$ Department of Cardiology, Centre of Postgraduate Medical Education, Grochowski Hospital, Warsaw, Poland \\ ${ }^{7}$ Department of Interventional Cardiology and Angiology, National Institute of Cardiology, Warsaw, Poland
}

Adv Interv Cardiol 2021; 17, 2 (64): 141-154

DOI: https://doi.org/10.5114/aic.2021.107492

\begin{abstract}
A bstract
Acute coronary syndrome is a factor for poor prognosis and recurrent cardiovascular events. Adequate antiplatelet therapy is crucial in patients with the acute coronary syndrome for risk reduction. Such treatment is well described in four documents issued by the European Society of Cardiology, which precisely illustrate the use of antiplatelets in the settings of ST-elevated and non-ST elevated myocardial infarction. Despite its unquestioned role in the treatment of acute coronary syndrome, recent real-world-data from Polish registries reveal poor adherence to the guidelines-recommended antiplatelet treatment in Poland. Thus, we present here a comprehensive review of the use of antiplatelets in the settings of the acute coronary syndrome. Each phase of the treatment, i.e. pre-hospital, in-hospital and post-hospital, is discussed separately for a better understanding of the decision-making process at each step. We also present unpublished data from Polish registries (e.g. PL-ACS 2019, National Registry of Procedures of Invasive Cardiology, RECEPTOmetrPEX panel) regarding adherence to the guidelines-recommended treatment in Poland, thus highlighting the points of care which should be immediately improved. It has to be stressed here that careful assessment of ischaemic and bleeding risk has to be performed in each patient with acute coronary syndrome individually and repeated at successive phases of the treatment. Only such an approach allows for appropriate antiplatelet therapy tailoring.
\end{abstract}

Key words: guidelines, antiplatelet treatment, ST elevation myocardial infarction, non-ST elevation myocardial infarction.

\section{Introduction}

Adequate antiplatelet treatment is crucial for ischaemic risk reduction in patients following acute coronary syndrome (ACS). However, the recent real-world data reveal poor adherence to the guidelines-recommended approach in Poland.

Thus, we present here a comprehensive review of antiplatelet treatment in successive phases of ACS treatment: pre-hospital, in-hospital and post-hospital. We also report the up-to-date antiplatelets usage statistics from Polish registries to highlight the points of care which should be immediately improved.

\section{The role of antiplatelet treatment in patients with acute coronary syndrome}

The occurrence of an ACS is an independent factor for poor prognosis in both short and long term observation. In-hospital mortality due to ACS in Poland, in the years 2009-2012, was at the level of $10.5 \%$ (6.3\% in patients undergoing percutaneous coronary intervention $(\mathrm{PCI})$ ), and mortality within 1 year after ACS was at the level of $19.4 \%$ (12.3\% in the PCl treated group) [1]. The most common cause of death in this group of patients are recurrent cardiovascular events. The highest risk of adverse events, including recurrent myocardial infarction, is observed dur-

Corresponding author:

Stanisław Tubek MD, PhD, Department of Heart Diseases, Wroclaw Medical University, Wroclaw, Poland, e-mail: stanislaw.tubek@gmail.com Received: 24.10.2020, accepted: 26.05.2021. 
ing the first months after ACS. The risk decreases gradually, reaching a plateau after about 3 years [2]. Stent thrombosis is responsible for $76.3 \%$ of the recurrent myocardial infarctions in a 30 -day observation and for $43.2 \%$ of the cases in an observation from 1 to 36 months after the coronary event [3]. Other causes of recurrent ACS are: the rupture of atherosclerotic lesions other than the primary culprit lesion, in-stent restenosis or progression of the coronary artery disease. A higher proportion of recurrent myocardial infarction was observed in patients with the ACS treated conservatively [4].

An efficient way to reduce the risk of recurrent myocardial infarction is an appropriate antiplatelet therapy. The standard of care after ACS, regardless of the method of its treatment (invasive vs. conservative), is dual antiplatelet therapy (DAPT) with acetylsalicylic acid (ASA, loading dose of 150-300 mg orally, followed by a maintenance dose of 75-100 mg orally; ASA may also be administered intravenously (loading dose 75-150 mg)) and one of the adenosine diphosphate $\mathrm{P} 2 \mathrm{Y}_{12}$ receptor inhibitors (Table I) [5]. According to the current guidelines, the antiplatelet drug of choice in ST-elevation myocardial infarction (STEMI) and non-ST elevation acute coronary syndrome (NSTE-
ACS), in the absence of contraindications, should be one of the new $\mathrm{P}_{2} \mathrm{Y}_{12}$ inhibitors, i.e. ticagrelor or prasugrel (Class I A recommendation for STEMI; I B for NSTE-ACS) $[6,7]$. Despite these recommendations, according to the Polish Registry of Acute Coronary Syndromes (PL-ACS), in 2018 clopidogrel was still the most commonly used P2Y $Y_{12}$ inhibitor in Polish patients with ACS.

It should be emphasised that ticagrelor and prasugrel have a stronger antiplatelet effect and less inter-individual variability in their potency $[8,9]$. The PLATO trial showed that ticagrelor, compared to clopidogrel, reduces the risk of recurrent myocardial infarction by $16 \%(\mathrm{HR}=$ $0.84(0.75-0.95))$, as well as death from any cause by $16 \%$ $(\mathrm{HR}=0.84(0.72-0.96))$ in 1-year observation [8]. These evidence-based data seem to be confirmed in everyday clinical practice based on the Swedish SWEDEHEART registry, which showed in 2016 that in the group of patients with myocardial infarction the use of ticagrelor instead of clopidogrel was associated with a decrease in the risk of recurrent myocardial infarction by $11 \%$ (corrected $\mathrm{HR}=0.89(0.78-1.01))$ and $\mathrm{a}$ decrease in the risk of death by $17 \%$ (corrected $H R=0.83(0.75-0.92)$ ) [10]. In the TRITON trial prasugrel was more effective than clopi-

Table I. Characteristics of $\mathrm{P}_{2} \mathrm{Y}_{12}$ inhibitors available in Poland (modified on the basis of 2020 ESC Guidelines for the management of acute coronary syndromes in patients presenting without persistent ST-segment elevation [7])

\begin{tabular}{|c|c|c|c|}
\hline Parameter & Clopidogrel & Prasugrel & Ticagrelor \\
\hline Chemical class & Thienopyridine & Thienopyridine & $\begin{array}{l}\text { Cyclopentyl-triazolopyrimi- } \\
\text { dine }\end{array}$ \\
\hline Dosage & $\begin{array}{l}\text { Loading dose } 600 \mathrm{mg} \text {, } \\
\text { then } 75 \mathrm{mg} / \text { day }\end{array}$ & $\begin{array}{l}\text { Loading dose } 60 \mathrm{mg} \text {, } \\
\text { then } 10 \mathrm{mg} / \text { day }\end{array}$ & $\begin{array}{l}\text { Loading dose } 180 \mathrm{mg} \text {, } \\
\text { then } 90 \mathrm{mg} \text { twice a day }\end{array}$ \\
\hline \multicolumn{4}{|l|}{ Dosage in CKD: } \\
\hline Stage 3 (eGFR 30-59 ml/min/1.73 m²) & No dose adjustment & No dose adjustment & No dose adjustment \\
\hline Stage 4 (eGFR $15-29$ ml/min/1.73 m²) & No dose adjustment & No dose adjustment & No dose adjustment \\
\hline Stage $5\left(\right.$ eGFR $\left.<15 \mathrm{ml} / \mathrm{min} / 1.73 \mathrm{~m}^{2}\right)$ & Limited data & Limited data & Limited data \\
\hline Reversibility of combination & Irreversible & Irreversible & Reversible \\
\hline Activation & $\begin{array}{c}\text { Prodrug, with variable liver } \\
\text { metabolism }\end{array}$ & $\begin{array}{l}\text { Prodrug, with predictable liver } \\
\text { metabolism }\end{array}$ & $\begin{array}{l}\text { Active drug, with additiona } \\
\text { active metabolite }\end{array}$ \\
\hline Onset of loading dose effect ${ }^{a}[\mathrm{~h}]$ & $2-6^{b}$ & $0.5-4^{b}$ & $0.5-2^{b}$ \\
\hline Duration of effect [days] & $3-10$ & $7-10$ & $3-5$ \\
\hline Withdrawal before surgery [days] & $5^{c}$ & $7^{c}$ & $3-5 c$ \\
\hline Plasma half-life of active $\mathrm{P} 2 \mathrm{Y}_{12}$ inhibitor $^{\mathrm{d}}$ & $30-60 \mathrm{~min}$ & $30-60$ mine $^{\mathrm{e}}$ & $6-12 \mathrm{~h}$ \\
\hline Inhibition of adenosine reuptake & No & No & Yes \\
\hline Main contraindications & - Active bleeding & $\begin{array}{l}\text { - Active bleeding } \\
\text { - Past ischaemic stroke } \\
\text { - Past intracranial haemor- } \\
\text { rhage } \\
\text { - Simultaneous long-term } \\
\text { anticoagulation }\end{array}$ & $\begin{array}{l}\text { - Active bleeding } \\
\text { - Past intracranial bleeding } \\
\text { - Simultaneous long-term } \\
\text { anticoagulation }\end{array}$ \\
\hline
\end{tabular}

$A D P$ - adenosine diphosphate, ATP - adenosine triphosphate, CKD - chronic kidney disease, eGFR - estimated glomerular filtration rate, ${ }^{a} A D P$-induced platelet aggregation inhibition in $\geq 50 \%$, bonset of action may be delayed if intestinal absorption is delayed (e.g. by opiates), "shortening may be considered if indicated by platelet function tests and low bleeding risk, "affecting the response to platelet transfusion, ${ }^{e}$ the distribution phase half-life is reported since it most likely reflects duration of clinically relevant plasma levels, while the corresponding elimination phase half-life is approximately $7 \mathrm{~h}$. 
dogrel in reducing rates of composite primary end-point (death from cardiovascular causes, nonfatal myocardial infarction, or nonfatal stroke $-\mathrm{HR}=0.81$; (0.73-0.90); $p<0.001)$ [9].

However, it should be emphasised that the bleeding risk associated with the use of new $\mathrm{P}_{2} \mathrm{Y}_{12}$ receptor inhibitors is higher $[8,9]$. Recently published results from a real-world, retrospective, large-cohort study conducted in US and Korea revealed that in a propensity-score matched population net adverse clinical events ratio (composite endpoint consisting of ischaemic events - recurrent myocardial infarction, revascularization or ischaemic stroke and haemorrhagic events - haemorrhagic stroke or gastrointestinal bleeding) did not differ between the ticagrelor and clopidogrel groups [11]. Among the secondary endpoints there were also no significant differences in the occurrence of ischaemic events, but haemorrhagic complications were significantly more frequent in the ticagrelor group. These inconsistencies between randomized trials, where ticagrelor was clearly better than clopidogrel, and carefully analysed data from real-world registries may have many reasons. One possible explanation is less precise $\mathrm{P}_{2} \mathrm{Y}_{12}$ inhibitor choice in everyday practice. For example, in the described real-word data analysis 3\% of patients received a combination of ticagrelor and an oral anticoagulant, which is contraindicated according to the current guidelines. The other reason may be the higher rate of new generation $\mathrm{P}_{2} \mathrm{Y}_{12}$ inhibitors' discontinuation rate, due to adverse effects or economic reasons. Finally, it has to be stressed that technical aspects of $\mathrm{PCl}$ have changed significantly since the results of PLATO and TRITON were published, which itself significantly reduced thrombotic complications following the procedure, thereby reducing possible advantages from use of more potent $\mathrm{P} 2 \mathrm{Y}_{12}$ inhibitors.

Therefore, it is necessary to individualise the antiplatelet therapy in patients with ACS in terms of both the choice of $\mathrm{P}_{2} \mathrm{Y}_{12}$ receptor inhibitor and the duration of the therapy.

\section{Pre-hospital phase of ACS}

Evidence from clinical trials is insufficient to give universal, precise guidelines for the time of DAPT initiation in the pre-hospital phase of ACS. However, the available observations seem to justify the earliest possible initiation of DAPT in patients with STEMI [5, 12]. On the other hand, the latest guidelines regarding the management of NSTE-ACS do not recommend routine pre-treatment with $\mathrm{P}_{2} \mathrm{Y}_{12}$ inhibitors (class III A recommendation) [7].

In clinical practice, the diagnosis of STEMI is based on ECG and typical clinical symptoms. Therefore, most patients with STEMI can be identified at the pre-hospital stage and, if eligible for primary $\mathrm{PCl}$ (time to $\mathrm{PCl} \leq 120 \mathrm{~min}$ since diagnosis), they should be immediately loaded with DAPT consisting of ASA and ticagrelor or prasugrel (clopi- dogrel is limited to cases where other $\mathrm{P}_{2} \mathrm{Y}_{12}$ inhibitors are contraindicated - see simplified algorithm in Figure 1 presenting the rules of pre-hospital $\mathrm{P}_{2} \mathrm{Y}_{12}$ selection) [6]. Under the Directive of the Ministry of Health of 20th April 2016, such authorisation is also granted to paramedic teams, who after the teletransmission of the ECG tracing and confirmation of the STEMI diagnosis, can administer ticagrelor or clopidogrel and acetylsalicylic acid before arriving at the hospital [12]. Prasugrel was not mentioned in this document. For patients eligible for thrombolysis (time to $\mathrm{PCl}>120$ min since diagnosis), which is rarely performed in Poland, the $\mathrm{P} 2 \mathrm{Y}_{12}$ receptor inhibitor of choice is clopidogrel in a loading dose of $300 \mathrm{mg}$ (then $75 \mathrm{mg} /$ day) in patients under the age of 75 or a loading dose of $75 \mathrm{mg}$ (then $75 \mathrm{mg} /$ day) in patients aged 75 or over [6].

The diagnosis of NSTE-ACS based on tests available outside the hospital is much more difficult and rarely possible without the result of troponin serum concentration. Other causes of chest pain such as pneumothorax, hypertensive crisis, aortic dissection or anaemia (leading to myocardial ischaemia) are a contraindication for DAPT. Moreover, data from recent trials and registries indicate that pre-treatment with $\mathrm{P}_{2} \mathrm{Y}_{12}$ inhibitors in patients with unknown coronary arteries anatomy increases bleeding risk with no influence on ischaemic risk. Thus, in the case of NSTE-ACS, antiplatelet drugs should not be administered in the pre-hospital phase [7].

From a practical point of view, it is worth noting some circumstances which may reduce the effectiveness of pre-hospital antiplatelet therapy. In vomiting patients, it is necessary to record how much time has passed since the administration of oral drugs and to describe the possible presence of undissolved tablets in vomit [12]. In such cases, DAPT re-loading should be considered individually. Another factor hindering the action of antiplatelet drugs are opiates, which have an inhibitory effect on gastrointestinal passage [6]. Therefore, morphine in patients with ACS should be used only for severe pain and in the lowest effective dose possible [6]. Moreover, crushing ticagrelor tablets or simultaneous intravenous metoclopramide administration may reduce this side effect. Both strategies have been proven to increase the availability of the drug and its antiplatelet effect [13, 14]. Recently available ticagrelor in soluble tablets could also be administered in vomiting or unconscious patients.

Data from the National Registry of Procedures of Invasive Cardiology (ORPKI) summarize the use of DAPT in the pre-hospital phase of ACS. In the period from September 2016 to August 2017 aspirin was administered in $72 \%$, clopidogrel in $51.3 \%$, ticagrelor in $2.3 \%$ and prasugrel in $0.4 \%$ of STEMI cases [15]. Thus, in this time period just over half of STEMI patients received DAPT in the pre-hospital stage. More recent data from the National Emergency Medical Services Management Support Sys- 


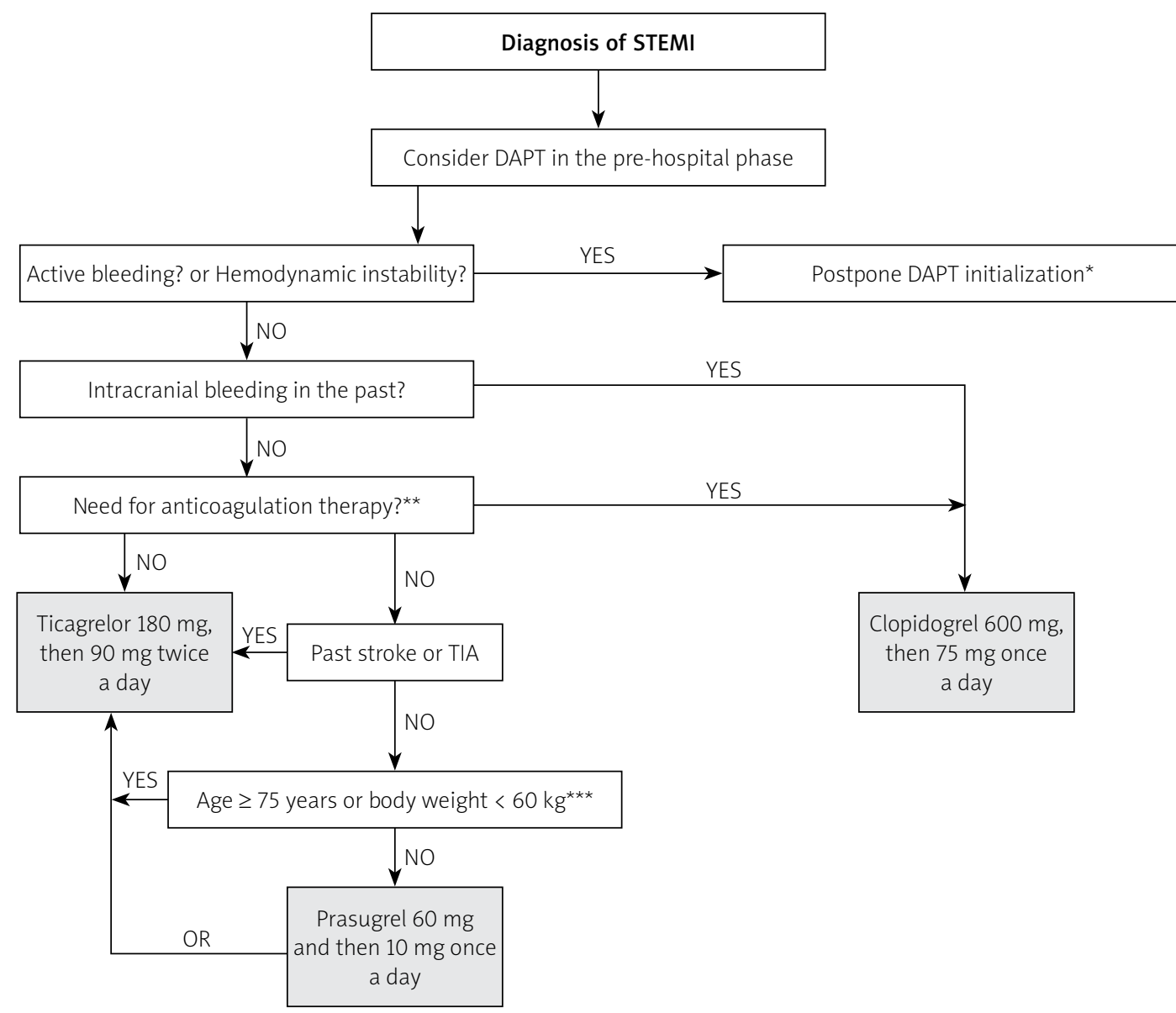

Figure 1. Simplified $\mathrm{P}_{2} \mathrm{Y}_{12}$ inhibitors treatment strategy for use in pre-hospital phase of ST-elevation myocardial infarction (STEMI)

STEMI - ST-elevation myocardial infarction, TIA - transient ischaemic attack. *DAPT should not be started in pre-hospital phase in actively bleeding patients; the approach should be individualized during the in-hospital phase according to the bleeding type. In haemodynamically unstable patients DAPT has to be considered carefully during the in-hospital phase since mechanical complications of STEMI or aortic dissection needs to be excluded first. ** Patients with atrial fibrillation or flutter, artificial mechanical heart valves, venous thromboembolism. ${ }^{* *} / n$ particular cases of these patients, where the benefits of prasugrel prescription overcome increased bleeding risk, the maintenance dose of $5 \mathrm{mg} /$ day may be used after loading with $60 \mathrm{mg}$.

tem (2018) reveal that already $72.1 \%$ of patients diagnosed with ACS in pre-hospital settings received DAPT. Clopidogrel was still the most frequently administered $\mathrm{P}_{2} \mathrm{Y}_{12}$ inhibitor (49.68\%) and ticagrelor was used in $25.14 \%$ of cases [16].

\section{In-hospital phase of ACS}

\section{Patients referred for invasive evaluation} of coronary arteries

In cases of STEMI, DAPT should be started as soon as possible after the diagnosis, but no later than at the time of PCl. It has to be emphasised that in patients who have been loaded with clopidogrel in the pre-hospital phase, and do not have contraindications for ticagrelor application, the switch to ticagrelor by loading with $180 \mathrm{mg}$ should be done immediately after admission to the hospital (regardless of the time since admission) (class I B recommendation) [6]. In patients with STEMI, who have not received DAPT in the pre-hospital phase, ticagrelor or prasugrel should be the $\mathrm{P}_{2} \mathrm{Y}_{12}$ inhibitor of choice [6] (selection of $\mathrm{P}_{2} \mathrm{Y}_{12}$ inhibitor as shown in Figure 1). After the primary $\mathrm{PCl}$, when blood test results are already available, careful bleeding risk assessment has to be performed (as described in the section Periprocedural bleeding risk assessment). In low-bleeding-risk patients ticagrelor or prasugrel should be preferred for further treatment, while in the high-bleeding-risk group ticagrelor and clopidogrel are the $P 2 Y_{12}$ inhibitors of choice. In patients with indications for chronic anticoagulation clopidogrel with aspirin should be administered during the in-hospital phase.

Otherwise, in the case of NSTE-ACS, current guidelines do not recommend administration of $\mathrm{P}_{2} \mathrm{Y}_{12}$ in patients planned for an early invasive approach before the coronarography [7]. After the procedure, when the anatomy of coronary arteries is known and the decision to perform $\mathrm{PCl}$ has been made, careful bleeding risk assessment has to be performed (as described in the section Periprocedural bleeding risk assessment). In patients with low bleeding risk one of the new generation $\mathrm{P}_{2} \mathrm{Y}_{12}$ inhibitors should be adminis- 
tered immediately before the angioplasty. In other cases clopidogrel should be prescribed [7]. An algorithm presenting the choice of $\mathrm{P}_{2} \mathrm{Y}_{12}$ inhibitor in NSTE-ACS patients is presented in Figure 2. It is worth noting that prasugrel should be preferred over ticagrelor in $\mathrm{P}_{2} \mathrm{Y}_{12}$ inhibitor-naïve patients, when not contraindicated (class Ila B recommendation). Such an approach is justified by the data from recent trials and registries showing that pre-treatment with $\mathrm{P} 2 \mathrm{Y}_{12}$ inhibitors in patients with unknown coronary arter- ies' anatomy increases bleeding risk with no influence on ischaemic risk and may postpone coronary artery bypass grafting (CABG) in particular cases. The predominance of the prasugrel-based, no pre-treatment strategy in the therapy of ACS was tested in the multi-centre, randomised, open-label ISAR-REACT 5 study. The study revealed that this strategy significantly reduces the main composite endpoint (all-cause deaths, myocardial infarction and stroke within 1 year after randomisation) with no influence on bleeding

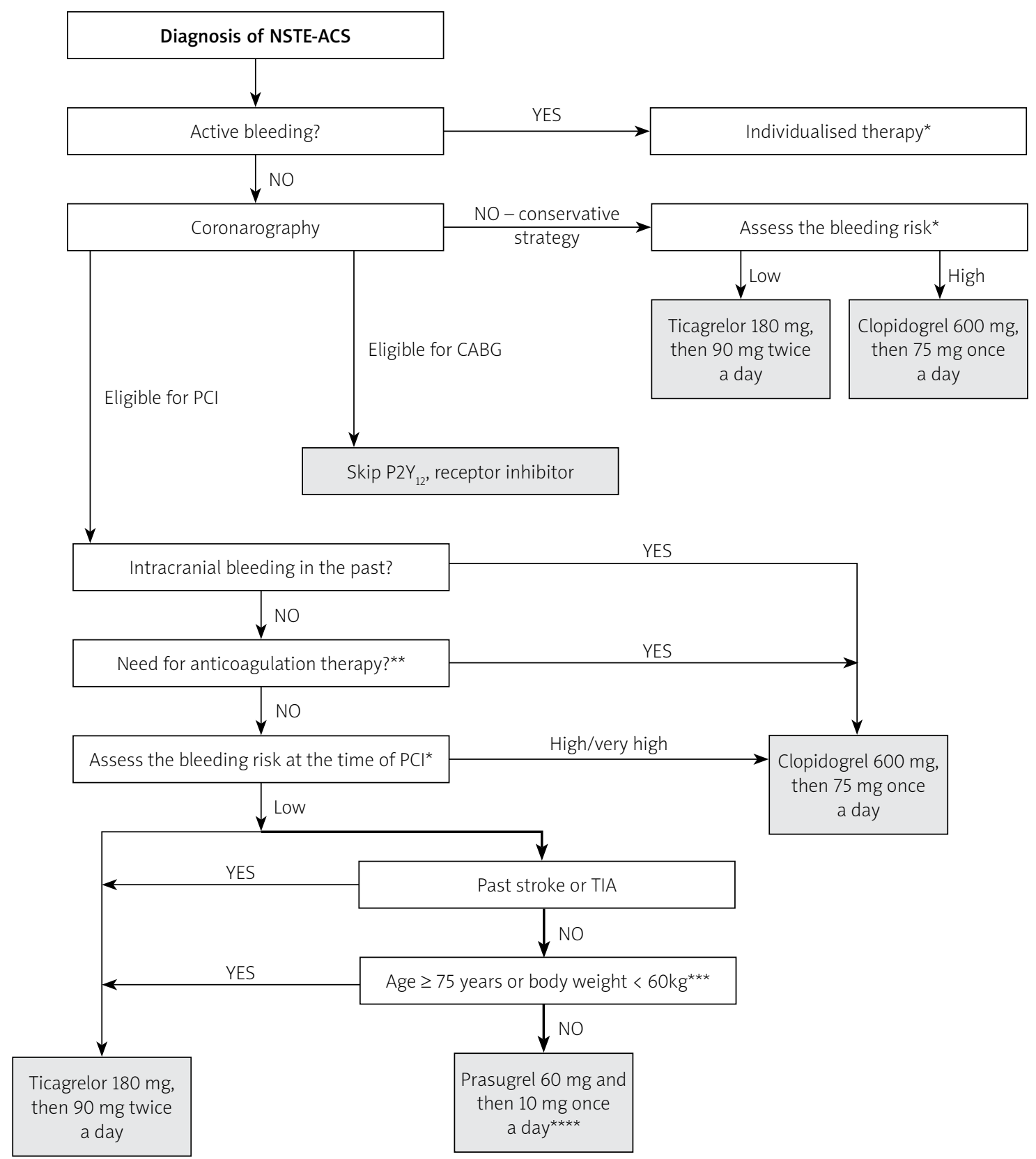

Figure 2. Simplified $\mathrm{P}_{2} \mathrm{Y}_{12}$ inhibitors treatment strategy for use during in-hospital phase of non-ST-elevation acute coronary syndrome (NSTE-ACS)

TIA - transient ischaemic attack. *High bleeding risk - PRECISE-DAPT $\geq 25$ points or presence of one major or two minor ARC-HBR criteria (see Table II): Very high bleeding risk - defined as a recent bleeding episode in the past month or planned, not deferrable surgery in the near future. ${ }^{* *}$ Patients with atrial fibrillation or flutter, artificial mechanical heart valves, venous thromboembolism. ${ }^{* *} / n$ particular cases of these patients, where the benefits of prasugrel prescription overcome increased bleeding risk, the maintenance dose of $5 \mathrm{mg} /$ day may be used after loading with $60 \mathrm{mg} .{ }^{* * * *}$ Prasugrel should be preferred over ticagrelor, when not contraindicated (class Ila B recommendation). 
risk, compared with the ticagrelor-based, pre-treatment strategy. The results of the study aroused great controversy as, although 1,299 (32.3\%) patients among the 4,018 randomized in the study did not receive the treatment according to the study protocol, the intention-to-treat analysis (analysis of the results in all randomized patients, according to the group to which they were originally assigned, regardless of the treatment applied) was used. The large proportion of patients whose treatment had been discontinued or changed, along with the open-label scheme of the trial and the lack of real supervision over the prescribed treatment (patients purchased the drugs individually), necessitate careful interpretation of the results $[17,18]$. It is also worth noting that ticagrelor has not been tested in the no-pre-treatment strategy so far. Despite these doubts, based on the study results, the latest NSTE-ACS guidelines propose prasugrel as the $\mathrm{P}_{2} \mathrm{Y}_{12}$ inhibitor of choice in NSTEACS patients.

Loading with a $\mathrm{P}_{2} \mathrm{Y}_{12}$ inhibitor before coronarography in the settings of NSTE-ACS may be considered only in low-bleeding risk patients referred for the delayed invasive strategy (class Ilb C recommendation). In such circumstances, only ticagrelor can be administered since prasugrel is prescribed only when the coronary anatomy is known $[19,20]$.

\section{Periprocedural bleeding risk assessment}

Current guidelines propose two approaches for the bleeding risk assessment in patients requiring DAPT - the PRECISE-DAPT scale or Academic Research Consortium for High Bleeding Risk (ARC-HBR) criteria. Both methods of assessment should be incorporated at the time of PCl using available blood test results, demographic data and records from patients' medical history.

The PRECISE-DAPT scale includes such parameters as a history of bleeding requiring medical attention, patient's age and laboratory test results: haemoglobin concentration, leucocytosis, creatinine clearance; these values should be collected close in time to the index procedure. A score of $\geq 25$ points suggests a high risk of bleeding complications, indicating the use of a less potent $\mathrm{P}_{2} \mathrm{Y}_{12}$ inhibitor, e.g. clopidogrel, and beneficial reduction of post-hospital DAPT duration. Results below 25 indicate the predominant risk of ischaemic complications and should result in prescription of a more potent P2 $\mathrm{Y}_{12}$ inhibitor, e.g. ticagrelor or prasugrel, and a standard or even prolonged DAPT period in the post-hospital phase [5]. The PRECISE-DAPT calculator can be found at www. precisedaptscore.com or downloaded as an application for Android or iOS smartphones. The PRECISE-DAPT scale has not been validated in patients treated with CABG.

Academic Research Consortium for High Bleeding Risk (ARC-HBR) criteria provide an interesting, simpler alternative to the PRECISE-DAPT scale for bleeding risk assessment in patients undergoing $\mathrm{PCl}$ [21]. High risk of bleed- ing is defined as the presence of one major risk factor or two minor risk factors listed in Table II at the time of $\mathrm{PCl}$.

\section{Patients with indications for chronic anticoagulation}

Chronic anticoagulant therapy accompanied with DAPT significantly increases the risk of haemorrhagic complications $[5,22]$. A less potent $P 2 Y_{12}$ inhibitor, e.g. clopidogrel, is a drug of choice in this group of patients with ACS; however, the duration and the composition of antiplatelet therapy (DAPT or monotherapy) should be individually tailored. Generally in all patients triple anticoagulant therapy should be prescribed during the hospital phase (up to 1 week after ACS) and followed by careful evaluation of the bleeding and ischaemic risk factors at the hospital discharge. According to this assessment further therapy is planned, as described in the section Hospital discharge and post-hospital phase.

\section{Data from Polish registries}

Recent unpublished data from the PL-ACS database (2019) on DAPT in invasively treated patients with ACS reveal that during the in-hospital phase of STEMI, aspirin was applied in $93.0 \%$ and one of the $\mathrm{P}_{2} \mathrm{Y}_{12}$ inhibitors in $86.0 \%$ of patients (clopidogrel was administered in $42.8 \%$ of cases, ticagrelor in $43.2 \%$ and prasugrel in $1.6 \%)$. In non-ST segment elevation myocardial infarction (NSTEMI), these proportions were as follows: aspirin was applied in $93.0 \%$ and a $\mathrm{P}_{2} \mathrm{Y}_{12}$ inhibitor in $78.3 \%$ of patients (clopidogrel in $55.6 \%$ of cases, ticagrelor in $22.7 \%$ and prasugrel in 1.2\%). The switch from clopidogrel to ticagrelor in the in-hospital phase was performed in $7.2 \%$ of patients. As clearly shown here, the use of new P2Y inhibitors in Poland is still rare, particularly in NSTEMI patients, despite the highest class of recommendation.

A separate group of ACS patients comprises those who, following the coronary angiography, are candidates for CABG. In the case of STEMI primary $\mathrm{PCl}$ is the preferred revascularization method and emergency CABG (usually after loading doses of DAPT) is performed rarely and only when PCI fails [6]. In NSTE-ACS, CABG could be preferred over $\mathrm{PCl}$ in selected cases depending on the coronary anatomy and risk assessment. In patients in whom, despite guidelines, DAPT was introduced and the surgery can be postponed, it is advisable to discontinue ticagrelor for a minimum of 3 days, clopidogrel for 5 days and prasugrel for 7 days before CABG, with continuous acetylsalicylic acid administration [5, 22]. DAPT should be restarted after surgery as soon as possible.

\section{Patients referred for conservative treatment}

In the case of patients with ACS, who are not eligible for invasive treatment, the $\mathrm{P} 2 \mathrm{Y}_{12}$ inhibitor of choice is ticagrelor. In the case of contraindications, high bleeding risk or indications for chronic oral anticoagulation, clopidogrel should be administered [5]. 
Table II. Academic Research Consortium for High Bleeding Risk criteria assessed at the time of percutaneous coronary intervention. Bleeding risk is high when one major or two minor criteria are met [20]

\begin{tabular}{|c|c|}
\hline Major criteria & Minor criteria \\
\hline Anticipated use of long-term OAC & Age $\geq 75$ years \\
\hline Severe or end-stage CKD (eGFR < $30 \mathrm{ml} / \mathrm{min})$ & Moderate CKD (eGFR 30-59 ml/min) \\
\hline Haemoglobin < $11 \mathrm{~g} / \mathrm{dl}$ & Haemoglobin 11-12.9 g/dl for men or 11-11.9 g/dl for women \\
\hline $\begin{array}{l}\text { Spontaneous bleeding requiring hospitalization and/or } \\
\text { transfusion in the past } 6 \text { months or at any time, if recurrent }\end{array}$ & $\begin{array}{l}\text { Spontaneous bleeding requiring hospitalization and/or } \\
\text { transfusion within the past } 12 \text { months not meeting the major cri- } \\
\text { terion }\end{array}$ \\
\hline Moderate or severe thrombocytopenia (platelet count $<100 \times 10^{9} /$ l) & $\begin{array}{l}\text { Chronic use of oral non-steroidal anti-inflammatory drugs } \\
\text { or steroids }\end{array}$ \\
\hline Chronic bleeding diathesis & Any ischaemic stroke at any time not meeting the major criterion \\
\hline \multicolumn{2}{|l|}{ Liver cirrhosis with portal hypertension } \\
\hline \multicolumn{2}{|l|}{$\begin{array}{l}\text { Active malignancy (excluding non-melanoma skin cancer) within the } \\
\text { past } 12 \text { months* }\end{array}$} \\
\hline \multicolumn{2}{|l|}{ Previous spontaneous intracranial haemorrhage (at any time) } \\
\hline \multicolumn{2}{|l|}{ Previous traumatic intracranial haemorrhage within the past 12 months } \\
\hline \multicolumn{2}{|l|}{ Presence of a brain arteriovenous malformation } \\
\hline \multicolumn{2}{|l|}{ Moderate or severe ischaemic stroke within the past 6 months } \\
\hline \multicolumn{2}{|l|}{ Recent major surgery or major trauma within 30 days prior to $\mathrm{PCI}$} \\
\hline Non-deferrable major surgery on DAPT & \\
\hline
\end{tabular}

\section{Hospital discharge and post-hospital phase}

The next critical point of the DAPT planning in patients with ACS is the time of the hospital discharge. Two problems have to be considered at this point - the duration of DAPT and the choice of a P2Y 12 inhibitor. Generally, DAPT following ACS should last 12 months, but this period may be shortened in a case of high bleeding risk (due to patient characteristics) or parallel anticoagulants use, or prolonged when high ischaemic risk (due to patient or procedure characteristics) dominates. Scrupulous reevaluation of ischaemic and bleeding risk of each patient is required followed by further therapy individualisation.

\section{High-bleeding-risk patients}

The PRECISE-DAPT scale or Academic Research Consortium for High Bleeding Risk (ARC-HBR) criteria as well as clinical observations made during the hospitalization e.g. drop in haemoglobin levels, bleeding events, new-onset atrial fibrillation - should be revised here carefully. In patients with high bleeding risk shortening of DAPT to 6 months in STEMI patients or to 3-6 months in NSTEACS should be considered and a less potent $\mathrm{P} 2 \mathrm{Y}_{12}$ should be preferred, as presented in Figure 3 for STEMI and Figure 4 for NSTE-ACS. It is worth noting that in some trials such as in SMART-CHOICE [23], which importantly influenced the latest version of the NSTE-ACS guidelines, patients with STEMI were also included since it seems to be reasonable to consider the shortening of DAPT to 3 month also in particular cases of high-bleeding-risk STEMI patients.

The new NSTE-ACS guidelines also permit the DAPT de-escalation strategy (switching to clopidogrel after initial administration of ticagrelor or prasugrel) to treat patients who are no longer suitable for more potent $\mathrm{P}_{2} \mathrm{Y}_{12}$ inhibitors, e.g. due to increased risk of bleeding (class IIb A recommendation) [7]. De-escalation may be guided by platelet function testing or CYP2C19 genotyping or even unguided, based on clinical assessment. It has to be stressed that the unguided approach and uniform de-escalation switching schemes have not been tested in clinical trials so far, since de-escalation should be performed carefully in selected patients and potential increased risk of ischaemic events needs to be considered. It seems to be reasonable to perform de-escalation after at least 1 month after ACS. Algorithms describing possible ways of P2Y ${ }_{12}$ inhibitor switching during DAPT, based on pharmacokinetic data, are shown in Figure 5.

\section{Low-bleeding-risk patients}

In low-bleeding-risk patients more potent $\mathrm{P}_{2} \mathrm{Y}_{12}$ inhibitors - ticagrelor or prasugrel in STEMI and prasugrel in NSTE-ACS - should be preferred, as presented in Figure 3 


\section{STEMI}
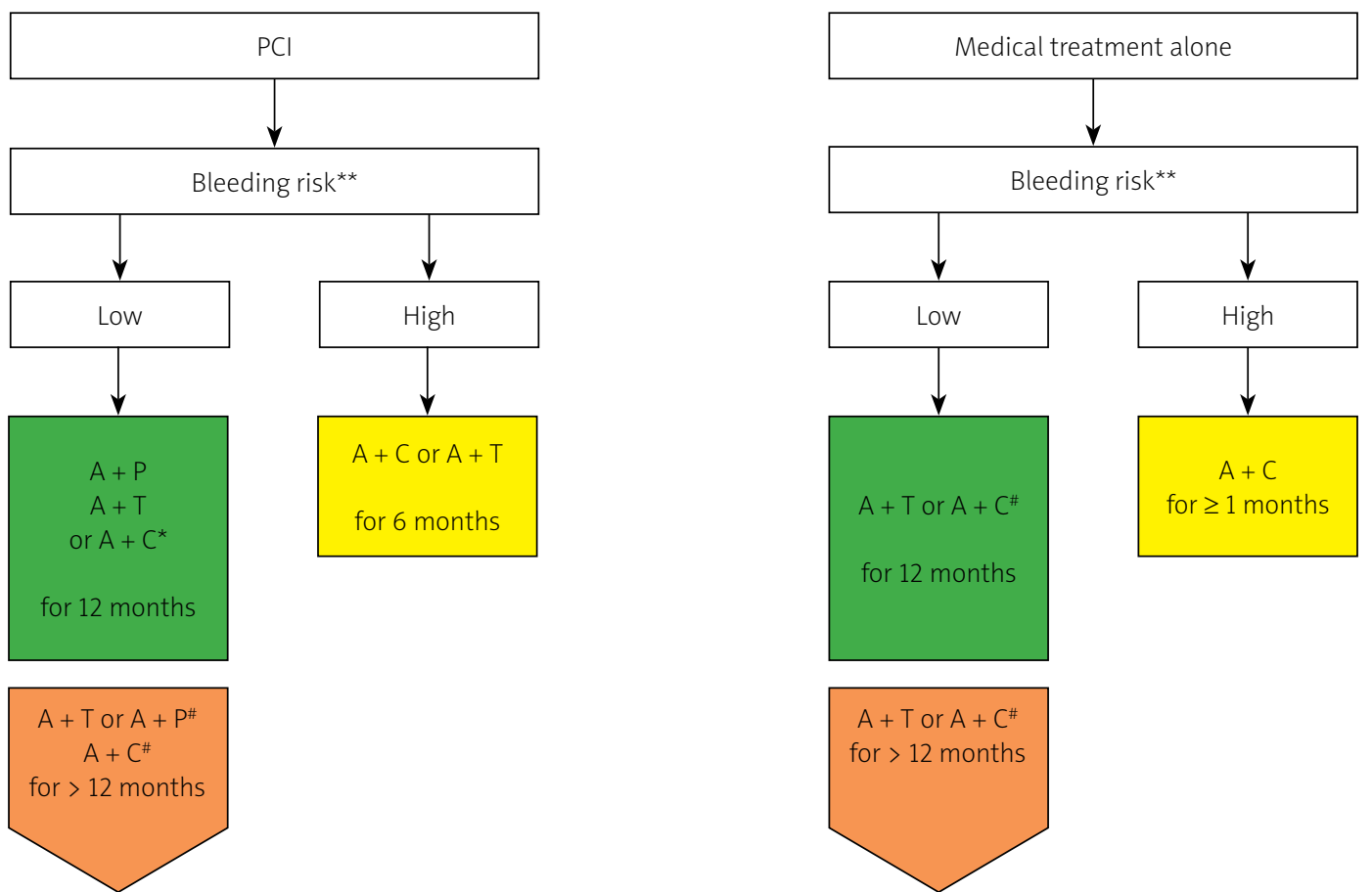

In low-bleeding and high-ischemic risk ACS patients with no prior stroke or TIA, who receive aspirin with clopidegrel, vascular-dose of rivaroxaban (2.5 mg b.i.d.) may be considered for approximately 1 year (Class IIb B recommendation) [1].

Figure 3. Algorithm for dual antiplatelet treatment in patients with ST-elevated myocardial infarction (STEMI) depending on the bleeding risk. (Modified on the basis of 2017 ESC focused update on dual antiplatelet therapy in coronary artery disease developed in collaboration with EACTS [5])

$\mathrm{PCl}$ - percutaneous coronary intervention, green - class I recommendation, yellow - IIa, orange - IIb. *If patient is not eligible for treatment with prasugrel or ticagrelor. **High bleeding risk - PRECISE-DAPT $\geq 25$ points or presence of one major or two minor ARC-HBR criteria (Table II). "If patient is not eligible for treatment with ticagrelor. $A$ - acetylsalicylic acid, C-clopidogrel, $T$-ticagrelor, $P$ - prasugrel.

for STEMI and Figure 4 for NSTE-ACS. Moreover, patients who were initially at low risk of bleeding, and if DAPT was well tolerated in the obligatory 12 -month period, may be considered for prolongation of the therapy.

According to the Focused update on DAPT Guidelines 2017, the use of the DAPT scale is suggested for DAPT prolongation in STEMI patients (a calculator is available at www.daptstudy.org or as an application for an Android or iOS smartphone). A score of 2 (or more points) indicates a high risk of thrombotic complications and supports potential benefits from DAPT prolongation (class IIb B recommendation), while a score of fewer than 2 points suggests lack of benefits from DAPT continuation.

A slightly different approach is proposed by the new NSTE-ACS guidelines 2020. Prolonged DAPT should be considered in patients without increased risk of major or life-threatening bleeding and high ischaemic risk (class Ila A recommendation) or may be considered in patients with a moderate risk of an ischaemic event (class IIb A recommendation). Ischaemic risk assessment is much more complicated than in previous guidelines discussed. A two- step approach is proposed: (1) in the first step the clinician stratifies the severity of individual patient coronary artery disease into complex or non-complex disease (the judgement is based on the patient's cardiovascular history and/ or coronary anatomy); (2) in the second step patient- and procedure-dependent ischaemic-risk-enhancing factors are analysed - see Table III for more details.

The preferred $\mathrm{P}_{2} \mathrm{Y}_{12}$ inhibitor for prolonged DAPT is ticagrelor, usually in a dose of $60 \mathrm{mg}$ twice a day (In the PEGASUS trial, such treatment was beneficial for up to 36 months after myocardial infarction, in patients aged $\geq 65$ years or $\geq 50$ years with one of the additional high-risk factors for ischaemic incidents, i.e. with diabetes mellitus requiring pharmacotherapy, with previous myocardial infarction, multivascular coronary disease or chronic kidney disease with GFR $<60 \mathrm{ml} / \mathrm{min}$ ) [24]. In all patients after ACS, ASA lifelong therapy should be introduced following DAPT discontinuation [5].

In low-bleeding- and low-ischaemic-risk NSTE-ACS patients the new treatment strategy consisting of 3 months of DAPT with aspirin and ticagrelor followed by 


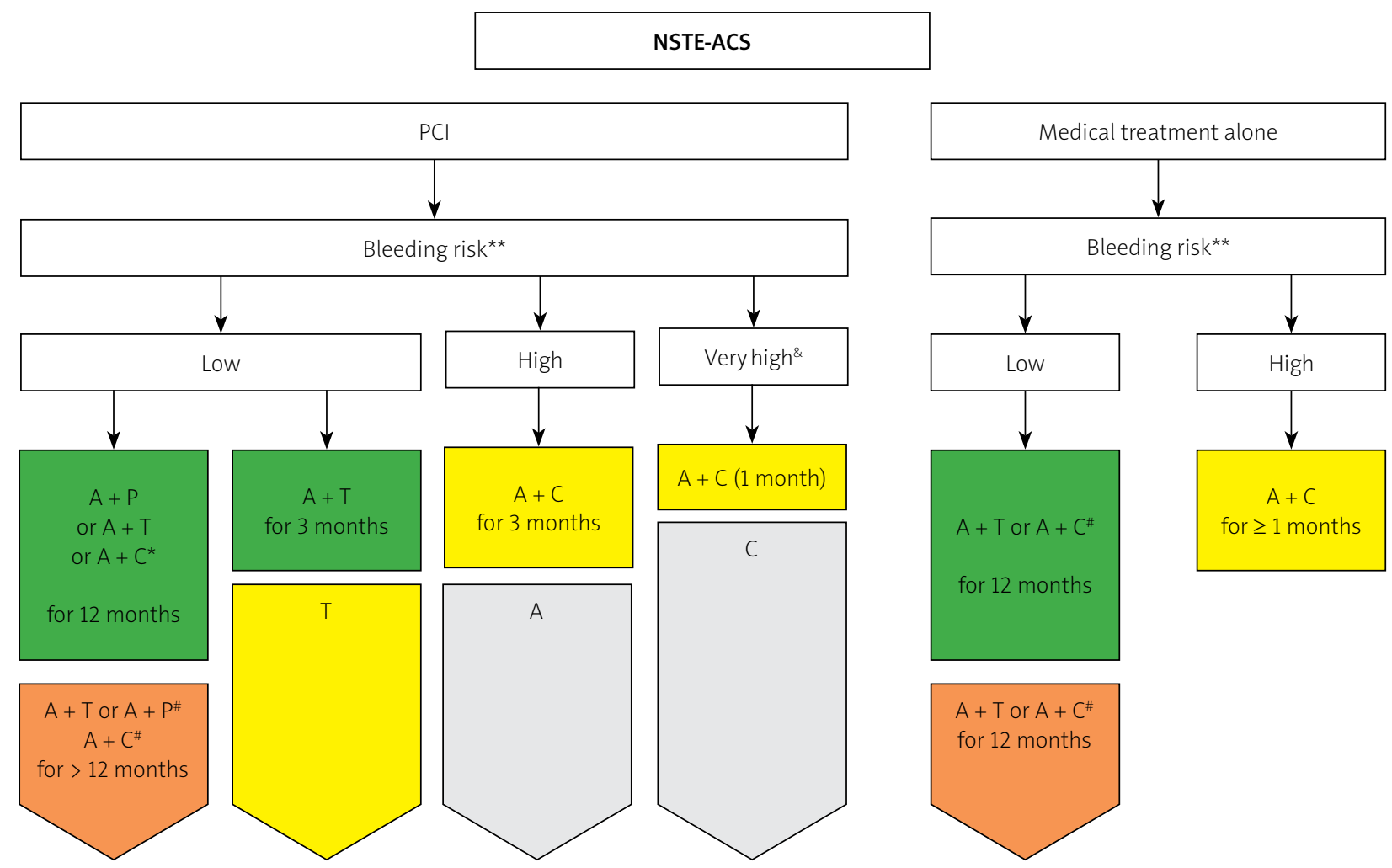

In low-bleeding and high-ischemic risk ACS patients with no prior stroke or TIA, who receive aspirin with clopidegrel, vascular-dose of rivaroxaban (2.5 mg b.i.d.) may be considered for approximately 1 year (Class IIb B recommendation) [1].

Figure 4. Novel approach for antiplatelet treatment in patients with NSTE-ACS (modified on the basis of 2020 ESC Guidelines for the management of acute coronary syndromes in patients presenting without persistent ST-segment elevation) [7])

\&Defined as a recent bleeding episode in the past month or planned, not deferrable surgery in the near future. *When prasugrel or ticagrelor is contraindicated. "If patient is not eligible for ticagrelor. ${ }^{* *} H i g h$ bleeding risk - PRECISE-DAPT $\geq 25$ points or presence of one major or two minor ARC-HBR criteria (Table II), green - class I recommendation, yellow - Ila, orange - IIb). A - acetylsalicylic acid, C - clopidogrel, T-ticagrelor, P-prasugrel.

ticagrelor monotherapy up to 12 months after the ACS should be considered [7]. Such an approach was tested in the TWILIGHT trial, where $64.8 \%$ of all 7119 randomized participants had NSTE-ACS and were generally low-ischaemic- and -bleeding-risk patients according to current criteria. The shortening of DAPT resulted in $44 \%$ reduction of haemorrhagic complications in the period from 3 to 12 months after $\mathrm{PCl}(\mathrm{HR}=0.56 ; 95 \% \mathrm{Cl}: 0.45-0.68$; $p<0.001$ ), defined as type 2,3 or 5 bleeding according to BARC. At the same time, this DAPT modification did not increase the prevalence of ischaemic events (secondary composite endpoint - death from any cause, stroke, myocardial infarction - HR 0.99; 95\% Cl: 0.75-1.25; $p<0.001$ for equivalence) [25].

\section{Patients with indications for chronic anticoagulation}

In the group of patients with indications for chronic anticoagulation the in-hospital triple therapy period should be followed by careful evaluation of bleeding and ischaemic risk factors at the hospital discharge. We do not have a dedicated scale evaluating the risk of bleeding and ischaemic events in this population; however, according to the latest NSTE-ACS guidelines, despite the lack of validation, the use of PRECISE-DAPT or ARC-HBR criteria is advised for the assessment of bleeding risk in NSTE-ACS patients [7]. Otherwise, the risk of ischaemic events is demonstrated by a subject's clinical characteristics and the complexity of coronary intervention, and may be assessed using the criteria listed in Table III [7]. Since there are no large randomized clinical trials on the topic, it seems to be reasonable to use the same criteria and algorithm for STEMI patients.

In patients with predominating bleeding risk factors the triple therapy used at hospital should be reduced at discharge to double therapy (anticoagulant + clopidogrel or aspirin) for 6 months followed by an anticoagulant alone. Otherwise in patients with ischaemic risk overbalancing bleeding risk triple therapy should be prolonged for 1 month after the hospital discharge and followed by double therapy (anticoagulant + clopidogrel or aspirin) up to 12 months after the ACS. In all other cases with no 
Table III. Patient- and procedure-dependent ischaemic-risk-enhancing criteria for extended treatment with DAPT (modified on the basis of 2020 ESC Guidelines for the management of acute coronary syndromes in patients presenting without persistent ST-segment elevation) [7]. The complexity of CAD is assessed by the clinician, who takes into consideration individual patient's ischaemic events history and coronary anatomy

\section{High thrombotic risk $=$ Complex $\mathrm{CAD}$ and at least 1 criterion}

\begin{tabular}{|c|c|}
\hline & and at least 1 criterion \\
\hline Diabetes mellitus requiring medication & Diabetes mellitus requiring medication \\
\hline History of recurrent $\mathrm{MI}$ & History of recurrent $\mathrm{Ml}$ \\
\hline Polyvascular disease (CAD plus PAD) & Polyvascular disease (CAD plus PAD) \\
\hline CKD with eGFR $15-59 \mathrm{ml} / \mathrm{min} / 1.73 \mathrm{~m}^{2}$ & CKD with eGFR $15-59 \mathrm{ml} / \mathrm{min} / 1.73 \mathrm{~m}^{2}$ \\
\hline \multicolumn{2}{|l|}{ Any multivessel CAD } \\
\hline \multicolumn{2}{|l|}{$\begin{array}{l}\text { Premature (< } 45 \text { years) or accelerated (new lesion within a 2-year } \\
\text { time frame) CAD }\end{array}$} \\
\hline \multicolumn{2}{|l|}{$\begin{array}{l}\text { Concomitant systemic inflammatory disease (e.g. human immuno- } \\
\text { deficiency virus, systemic lupus erythematosus, chronic arthritis) }\end{array}$} \\
\hline \multicolumn{2}{|l|}{ Technical aspects: } \\
\hline \multicolumn{2}{|l|}{ At least 3 stents implanted } \\
\hline \multicolumn{2}{|l|}{ At least 3 lesions treated } \\
\hline \multicolumn{2}{|l|}{ Total stent length > $60 \mathrm{~mm}$} \\
\hline \multicolumn{2}{|l|}{$\begin{array}{l}\text { History of complex revascularization (left main, bifurcation stenting } \\
\text { with } \geq 2 \text { stents implanted, chronic total occlusion, stenting of last } \\
\text { patent vessel) }\end{array}$} \\
\hline \multicolumn{2}{|l|}{ History of stent thrombosis on antiplatelet treatment } \\
\hline Prolonged DAPT should be considered (class Ila A recommendation) & Prolonged DAPT may be considered (class IIb A recommendation) \\
\hline
\end{tabular}

\section{Moderate thrombotic risk $=$ Non-complex $C A D$} and at least 1 criterion

Table IV. Strategies to avoid bleeding complications in ACS patients treated with oral anticoagulant (modified on the basis of 2017 ESC focused update on dual antiplatelet therapy in coronary artery disease developed in collaboration with EACTS [1] and 2020 ESC Guidelines for the management of acute coronary syndromes in patients presenting without persistent ST-segment elevation [2])

Radial artery approach as default vascular access

In patients on OAC

a. $\mathrm{PCl}$ performed without interruption of VKAs or NOACS

b. In patients on VKAs, do not administer UFH if INR $>2.5$

c. In patients on NOACs, regardless of the timing of the last administration of NOACs, add low-dose parenteral anticoagulation (e.g. enoxaparin $0.5 \mathrm{mg} / \mathrm{kg}$ i.v. or UFH $60 \mathrm{IU} / \mathrm{kg}$ )

GP IIb/IIla inhibitors only for bailout or periprocedural complications

Assess ischaemic and bleeding risks using validated scales (e.g. $\mathrm{CHA}_{2} \mathrm{DS}_{2}$-VASc, HAS-BLED) with focus on modifiable risk factors and verify the indications for anticoagulation

Clopidogrel is $P 2 Y_{12}$ antagonist of choice

Use low-dose acetylsalicylic acid ( $\leq 100 \mathrm{mg}$ daily)

Stop triple therapy as soon as possible

Consider NOACs instead of VKA

Consider a target INR in the lower part of the recommended target range and maximise time in therapeutic range (i.e. > 65-70\%) when VKA is used

Consider the lower NOAC regimen tested in approval trials, and apply other NOAC regimens based on drug-specific criteria for its accumulation

Prescribe PPI routinely

ACS - acute coronary syndrome patients, UFH - unfractionated heparin, OAC - oral anticoagulant, NOAC - non-vitamin K oral anticoagulant, INR - international normalized ratio, $\mathrm{PPI}$ - proton-pump inhibitor, $\mathrm{PCl}$ - percutaneous coronary intervention, VKA - vitamin K antagonist. 


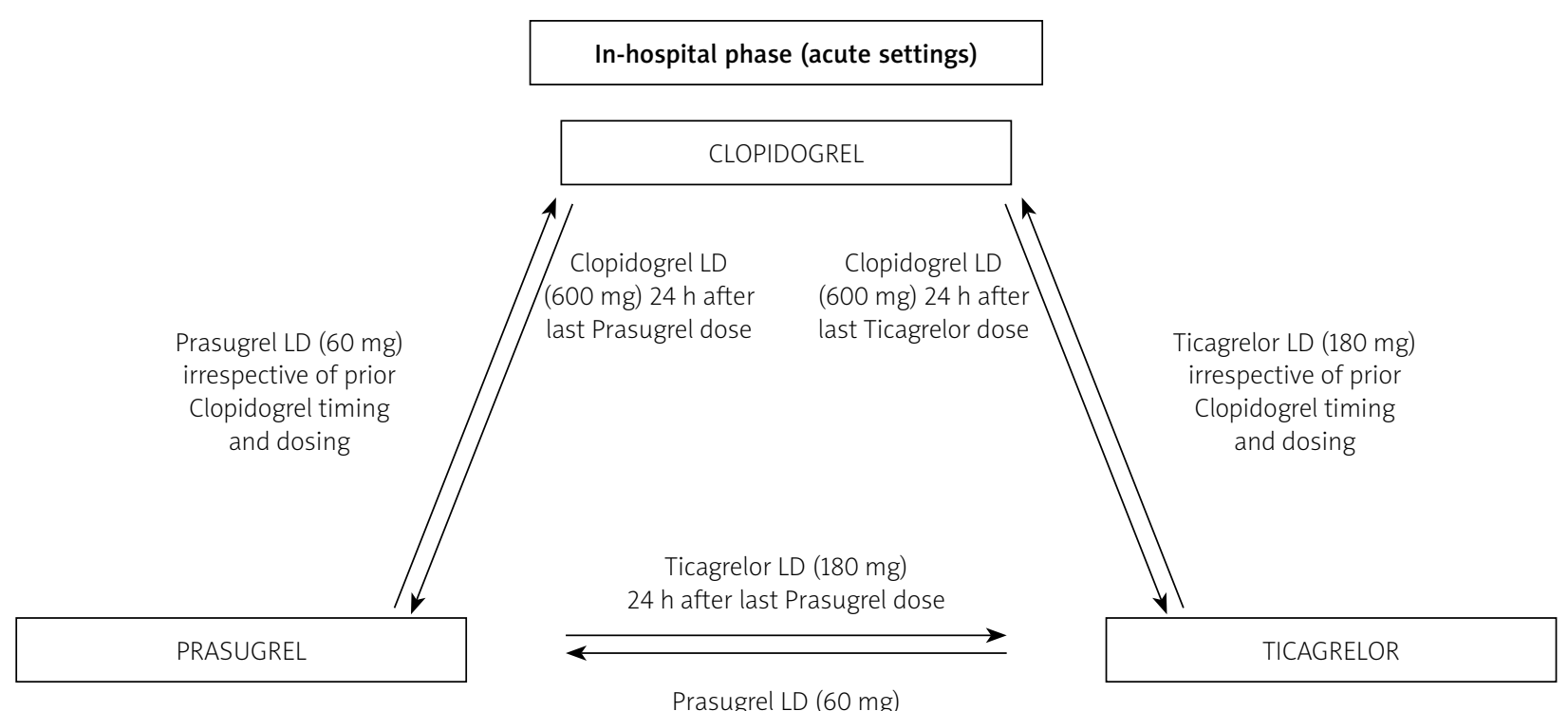

$24 \mathrm{~h}$ after last Ticagrelor dose

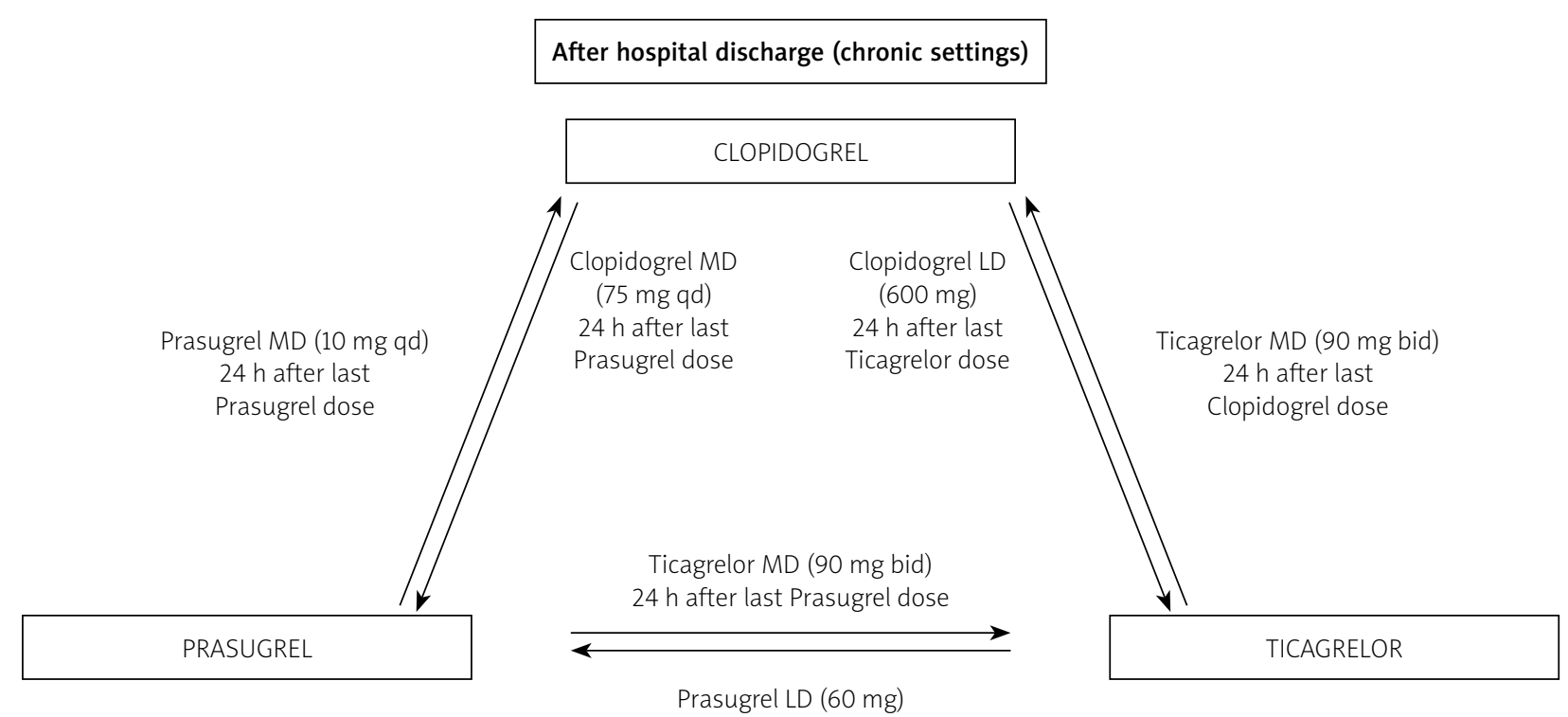

$24 \mathrm{~h}$ after last Ticagrelor dose

Figure 5. Algorithm for switching between oral $\mathrm{P}_{2} \mathrm{Y}_{12}$ inhibitors in the in-hospital and out-of-hospital settings (modified on the basis of 2017 ESC focused update on dual antiplatelet therapy in coronary artery disease developed in collaboration with EACTS [5])

predomination of either ischaemic or bleeding risk triple therapy should be reduced at discharge to double therapy (anticoagulant + clopidogrel or aspirin) for 12 months. One year after ACS in all cases antiplatelets should be withdrawn and the therapy should be limited to an oral anticoagulant [7]. The principles of antiplatelet treatment in anticoagulated patients with ACS and the algorithm facilitating the selection of antiplatelet therapy duration are presented in Table IV and Figure 6.

\section{Planning long-term P2Y $\mathrm{Y}_{12}$ inhibitor therapy}

When planning long-term therapy one has to remember about the most common reasons for the discontin- uation of particular $\mathrm{P}_{2} \mathrm{Y}_{12}$ inhibitors. It was shown in a recent meta-analysis of randomised clinical trials that as many as $25 \%$ of patients prescribed with ticagrelor stopped taking the medication prematurely. This was significantly more frequently compared to clopidogrel cessation [26]. The analysis of Polish prescription data (RECEPTOmetrPEX panel) showed that $37 \%$ of patients discontinued ticagrelor therapy after 1 month, and the therapy duration was less than 60 days in nearly half of the patients. Furthermore, after premature discontinuation of ticagrelor therapy, $57 \%$ of patients did not take any $\mathrm{P}_{2} \mathrm{Y}_{12}$ inhibitors. The most common cause of premature discontinuation of ticagrelor worldwide was its 


\section{AF patients undergoing $\mathrm{PCl}$ for $\mathrm{ACS}$}

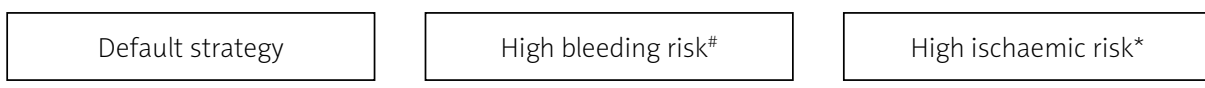

In-hospital (up to 1 week)
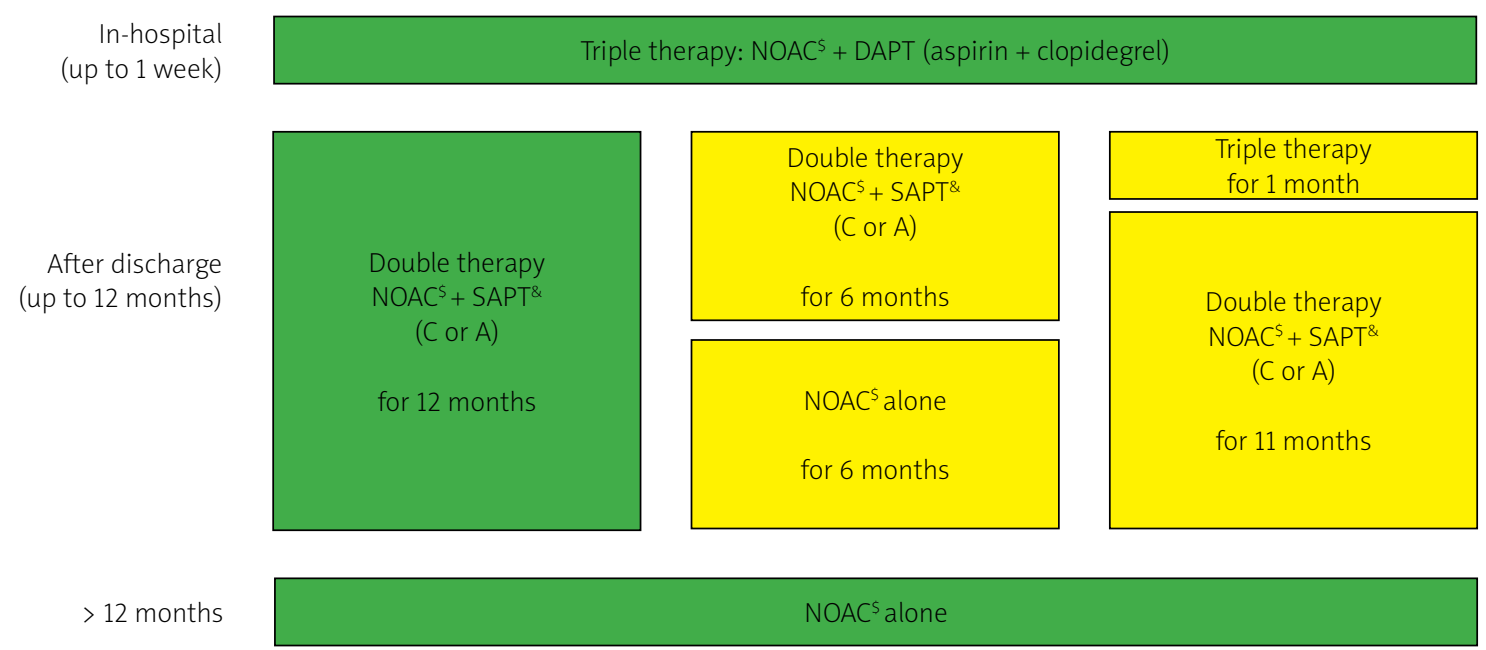

Figure 6. Algorithm for dual antiplatelet therapy in $\mathrm{PCl}$-treated acute coronary syndrome patients with an indication for chronic oral anticoagulation (modified on the basis of 2020 ESC Guidelines for the management of acute coronary syndromes in patients presenting without persistent ST-segment elevation [7])

A - acetylsalicylic acid, C - clopidogrel, T-ticagrelor, P-prasugrel, NOAC - non-vitamin K oral anticoagulant, DAPT - dual antiplatelet treatment, SAPT - single antiplatelet treatment, PCI - percutaneous coronary intervention, ACS - acute coronary syndrome. "assessed using PRECISE-DAPT sCale or ARCHBR criteria, *assessed with criteria listed in Table III, ${ }^{5}$ NOACS are preferred when not contraindicated, ${ }^{*}$ in SAPT clopidogrel is preferred [29], green - class I recommendation, yellow - Ila, orange - IIb.

side effects, such as bleeding, dyspnoea and sporadically bradyarrhythmia. The high cost of the medication and its twice-daily dosage regimen are also significant [26]. Patients' education regarding possible side effects, including dyspnoea, is very important. Dyspnoea associated with ticagrelor application decreases with time or even disappears completely and, most importantly, it does not influence the effectiveness of the treatment [27]. Possible predictors of this side effect are currently studied, which may help to identify patients who will suffer due to the phenomenon. Generally switching between different types of $\mathrm{P}_{2} \mathrm{Y}_{12}$ inhibitors should be avoided, since the only replacement whose safety has been confirmed in clinical trials is the switch from clopidogrel to ticagrelor in an acute phase of cardiac infarction. However, in specific clinical scenarios (bleeding, persistent severe dyspnoea, initiation of oral anticoagulation, poor economic situation, etc.) other drug changes are required. Algorithms describing possible ways of $\mathrm{P}_{2} \mathrm{Y}_{12}$ inhibitor switching during DAPT, based on pharmacokinetic data, are shown in Figure 5 [5].

\section{Data from Polish registries}

Data from the PL-ACS (2019) database show the structure of antiplatelet treatment at discharge in Polish patients with ACS. After PCl-treated STEMI 9.1\% of patients were discharged on triple antithrombotic thera- py, $84.5 \%$ on DAPT, $5.9 \%$ with a single antiplatelet drug, and $0.5 \%$ without any antiplatelet treatment. Following PCI-treated NSTEMI triple therapy was administered to $13.6 \%$ of patients, DAPT to $78.0 \%$, monotherapy to $7.9 \%$, and $0.6 \%$ of patients were discharged without any antiplatelet treatment. Worth noting in 2019 is the change of the leading combination of DAPT prescribed following STEMI compared to previous years. For the first time in Poland, the combination of aspirin and ticagrelor was the most frequently prescribed one (in $53.4 \%$ of patients) and outstripped aspirin with clopidogrel (prescribed in $44 \%$ ). Aspirin with prasugrel was prescribed only in $2.6 \%$. However, among NSTEMI patients the combination of aspirin with clopidogrel was still the most prescribed one $(61.4 \%)$. Aspirin with ticagrelor or aspirin with prasugrel was recommended in $36.3 \%$ and $2.3 \%$ of patients respectively. The duration of DAPT, in patients without anticoagulation, advised at the discharge was usually 12 months (in $93.0 \%$ of patients with STEMI and in $91.8 \%$ with NSTEMI); less frequently a longer period $(3.9 \%$ of patients with STEMI and $3.9 \%$ with NSTEMI) or shorter period $(3.1 \%$ of patients with STEMI and $4.1 \%$ with NSTEMI) was suggested. Unfortunately, and inconsistently with current guidelines, the same 12-month DAPT period was most frequently recommended in patients on anticoagulants (in $61.6 \%$ of patients with STEMI and in $55.9 \%$ with NSTEMI). Less frequently, 6-month (in $18.2 \%$ 
of patients with STEMI and in $20.2 \%$ with NSTEMI) and 1-2-month periods (in $9.9 \%$ of patients with STEMI and in $14.6 \%$ with NSTEMI) were suggested [28].

\section{Summary}

Appropriately tailored DAPT is a key to the successful treatment of ACS. According to the recent guidelines careful assessment of ischaemic and bleeding risk has to be performed in each patient individually and repeated at successive phases of the treatment. According to the risk assessed and clinician's intuition, the therapy should be individualized using the following variables: (1) choice of the $P 2 Y_{12}$ receptor inhibitor, (2) the composition of antiplatelet therapy (dual or single blockade) and (3) the period of treatment (from 1 week of DAPT to $>12$ months).

\section{Conflict of interest}

Andrzej Budaj - personal fees and non-financial support from Astra Zeneca, Bristol Myers Squibb/Pfizer, Sanofi Aventis, Bayer. Krzysztof Reczuch - personal fees from Astra Zeneca, Pfizer, Sanofi Aventis. Other authors declare no conflict of interest.

\section{References}

1. Gierlotka M, Zdrojewski T, Wojtyniak B, et al. Incidence, treatment, in-hospital mortality and one-year outcomes of acute myocardial infarction in Poland in 2009-2012 - nationwide AMI-PL database. Pol Heart J 2015; 73: 142-58.

2. Smolina K, Wright FL, Rayner M, Goldacre MJ. Long-term survival and recurrence after acute myocardial infarction in England, 2004 to 2010. Circ Cardiovasc Qual Outcomes 2012; 5: 532-40.

3. Stone SG, Serrao GW, Mehran R, et al. Incidence, predictors, and implications of reinfarction after primary percutaneous coronary intervention in ST-segment elevation myocardial infarction: the harmonizing outcomes with revascularization and stents in acute myocardial infarction trial. Circ Cardiovasc Interv 2014; 7: 543-51.

4. Lopes RD, Leonardi S, Neely B, et al. Spontaneous MI after nonST-segment elevation acute coronary syndrome managed without revascularization: the TRILOGY ACS trial. J Am Coll Cardiol 2016; 67: 1289-97.

5. Valgimigli M, Bueno H, Byrne RA, et al. 2017 ESC focused update on dual antiplatelet therapy in coronary artery disease developed in collaboration with EACTSThe Task Force for dual antiplatelet therapy in coronary artery disease of the European Society of Cardiology (ESC) and of the European Association for Cardio-Thoracic Surgery (EACTS). Eur Heart J 2018; 39: 213-60.

6. Ibanez B, James S, Agewall S, et al. 2017 ESC Guidelines for the management of acute myocardial infarction in patients presenting with ST-segment elevation: the Task Force for the management of acute myocardial infarction in patients presenting with ST-segment elevation of the European Society of Cardiology (ESC). Eur Heart J 2018; 39: 119-77.

7. Collet JP, Thiele H, Barbato E, et al. 2020 ESC Guidelines for the management of acute coronary syndromes in patients presenting without persistent ST-segment elevation: The Task Force for the management of acute coronary syndromes in patients presenting without persistent ST-segment elevation of the European Society of Cardiology (ESC). Eur Heart J 2021; 42: 1289-367.

8. Wallentin L, Becker RC, Budaj A, et al. Ticagrelor versus clopidogrel in patients with acute coronary syndromes. $N$ Engl J Med 2009; 361: 1045-57.

9. Wiviott SD, Braunwald E, Mccabe CH, et al. Prasugrel versus clopidogrel in patients with acute coronary syndromes. N Engl J Med 2007; 357: 2001-15.

10. Sahlén A, Varenhorst C, Lagerqvist B, et al. Outcomes in patients treated with ticagrelor or clopidogrel after acute myocardial infarction: experiences from SWEDEHEART registry. Eur Heart J 2016; 37: 3335-42.

11. You SC, Rho Y, Bikdeli B, et al. Association of ticagrelor vs clopidogrel with net adverse clinical events in patients with acute coronary syndrome undergoing percutaneous coronary intervention. JAMA 2020; 324: 1640-50.

12. Kubica J, Adamski P, Paciorek P, et al. Treatment of patients with acute coronary syndrome: recommendations for medical emergency teams: focus on antiplatelet therapies. Updated experts' standpoint. Cardiol J 2018; 25: 291-300.

13. Sikora J, Niezgoda P, Barańska M, et al. METoclopramide Administration as a Strategy to Overcome MORPHine-ticagrelOr Interaction in PatientS with Unstable Angina PectorlS - The METAMORPHOSIS Trial. Thromb Haemost 2018; 118: 2126-33.

14. Parodi G, Xanthopoulou I, Bellandi B, et al. Ticagrelor crushed tablets administration in STEMI patients: the MOJITO study. J Am Coll Cardiol 2015; 65: 511-2.

15. Rakowski T, Siudak Z, Dziewierz A, et al. Contemporary use of P2Y12 inhibitors in patients with ST-segment elevation myocardial infarction referred to primary percutaneous coronary interventions in Poland: data from ORPKI national registry. J Thromb Thrombol 2018; 45: 151-7.

16. Nadolny K, Ładny JR, Gałązkowski R, et al. Medical emergency team interventions in patients with ST-segment elevation myocardial infarction throughout Poland in 2018. Kardiol Pol 2020; 78: 292-9.

17. Schüpke S, Neumann FJ, Menichelli M, et al. Ticagrelor or prasugrel in patients with acute coronary syndromes. N Engl J Med 2019; 381: 1524-34.

18. Ostrowska M, Adamski P, Kubica J. ISAR-REACT 5 - czy to badanie powinno zmienić praktykę kliniczną? Folia Cardiol 2019; 14: 483-7.

19. Roffi M, Patrono C, Collet JP, et al. 2015 ESC Guidelines for the management of acute coronary syndromes in patients presenting without persistent ST-segment elevation: task force for the management of acute coronary syndromes in patients presenting without persistent ST-segment elevation of the European Society of Cardiology (ESC). Eur Heart J 2016; 37: 267-315.

20. Montalescot G, Bolognese L, Dudek D, et al. Pretreatment with prasugrel in non-ST-segment elevation acute coronary syndromes. N Engl J Med 2013; 369: 999-1010.

21. Urban P, Mehran R, Colleran R, et al. Defining high bleeding risk in patients undergoing percutaneous coronary intervention: a consensus document from the Academic Research Consortium for High Bleeding Risk. Eur Heart J 2019; 40: 2632-53.

22. Neumann FJ, Sousa-Uva M, Ahlsson A, et al. 2018 ESC/EACTS Guidelines on myocardial revascularization. Eur Heart J 2018; 40: 87-165.

23. Hahn JY, Song YB, Oh JH, et al. Effect of P2Y12 inhibitor monotherapy vs dual antiplatelet therapy on cardiovascular events 
in patients undergoing percutaneous coronary intervention: the SMART-CHOICE randomized clinical trial. JAMA 2019; 321: 2428-37.

24. Dellborg M, Bonaca MP, Storey RF, et al. Efficacy and safety with ticagrelor in patients with prior myocardial infarction in the approved European label: insights from PEGASUS-TIMI 54. Eur Heart J Cardiovasc Pharmacother 2019; 5: 200-6.

25. Mehran R, Baber U, Sharma SK, et al. Ticagrelor with or without aspirin in high-risk patients after PCI. N Engl J Med 2019; 381: 2032-42.

26. Arora S, Shemisa K, Vaduganathan M, et al. Premature ticagrelor discontinuation in secondary prevention of atherosclerotic CVD: JACC review topic of the week. J Am Coll Cardiol 2019; 73: 2454-64.

27. Storey RF, Becker RC, Harrington RA, et al. Characterization of dyspnoea in PLATO study patients treated with ticagrelor or clopidogrel and its association with clinical outcomes. Eur Heart J 2011; 32: 2945-53.

28. Hudzik B, Budaj A, Gierlotka M, et al. Assessment of quality of care of patients with ST-segment elevation myocardial infarction. Eur Heart J Acute Cardiovasc Care 2020; 9: 893-901.

29. Lip GYH, Collet JP, Haude M, et al. 2018 Joint European consensus document on the management of antithrombotic therapy in atrial fibrillation patients presenting with acute coronary syndrome and/or undergoing percutaneous cardiovascular interventions: a joint consensus document of the European Heart Rhythm Association (EHRA), European Society of Cardiology Working Group on Thrombosis, European Association of Percutaneous Cardiovascular Interventions (EAPCI), and European Association of Acute Cardiac Care (ACCA) endorsed by the Heart Rhythm Society (HRS), Asia-Pacific Heart Rhythm Society (APHRS), Latin America Heart Rhythm Society (LAHRS), and Cardiac Arrhythmia Society of Southern Africa (CASSA). Europace 2019; 21: 192-3. 